\title{
Artificial Intelligence, Employee Engagement, Fairness, and Job Outcomes
}

\section{Introduction}

The use of artificial intelligence (AI) to manage employees is becoming increasingly popular. In this chapter, AI is defined as the ability of a computer system to sense, reason, and respond to the environment. Computer systems with advanced AI can engage in sensing, reasoning, and responding in the most complex and dynamic environments. Other terms used to describe the use of AI to manage employees include algorithm management (O'Connor, 2016). These systems are being adapted by organizations at a rapid pace to help manage their workforce (Gerlsbeck, 2018; Kolbjørnsrud, Amico, \& Thomas, 2016). The reason for their popularity is twofold. First, organizations now have access to huge amounts of data (i.e., big data) about their business operations which can be leveraged to make more efficient and effective management decisions. Second, advances in AI now afford organizations the ability to capture and process this data in real-time. Organizations can now incorporate the latest information into their decision making even in the most complex and dynamic competitive markets. Despite this, management through AI also presents new challenges to employees who are now both directed and held accountable by AI.

Employee engagement is essential to the health and productivity of an organization, yet it is a great challenge faced by organizations globally. Recent research by Gallup Management Journal reveals that $29 \%$ of employees are actively engaged, 54\% are not engaged, and 17\% are disengaged (Rao, 2017). In light of these issues compounded by the introduction and integration of new technologies such as AI into the workplace, focusing on best practices and tools that enable employees to bring a full range of cognitive, emotional, and physical energies into their work roles is of critical importance (Shuck, Adelson, \& Reio, 2017).

This chapter seeks to identify the challenges faced by organizations that employ these new AI systems as they relate to employee engagement and offer suggestions to meet those challenges. This chapter defines employee engagement as the degree to which employees are motivated and passionate about their work. To accomplish this, the chapter provides several things: it presents the basic underlining concepts behind employee engagement, the factors needed to ensure that AI promotes employee engagement are discussed - trust and risk, fairness, the important technology characteristics, and issues of AI control and 
its impact on employee outcomes such as job satisfaction, meaningfulness, and retention.

\section{Employee Engagement}

\section{What Is Employee Engagement?}

The many definitions of employee engagement available sometimes results in conflated and confused meanings (Saks, 2006; Shuck, Osam, Zigarmi, \& Nimon, 2017). All seem to derive from the core definition of engagement. According to Merriam Webster, engagement is defined as "tending to draw favorable attention or interest." Other definitions include "to occupy the attention or efforts of a person or persons" or "to attract and hold fast" (see Dictionary.com). Similar definitions have been applied to employee engagement. Rothbard (2001) defined it as a psychological presence of attention and absorption. One of the earliest definitions offered by Kahn (1990) defines it as when an employee applies him/ herself physically, cognitively, and emotionally toward their work. More recently, HRD scholars have defined the terms as a "positive, active, workrelated psychological state operationalized by the maintenance, intensity, and direction of cognitive, emotional, and behavioral energy" (Shuck et al., 2017, p. 269). Taken together, all definitions involve some form of motivation and affect toward that motivation. In other words, employees are not only willing to allocate effort and time toward their work but do so in part because they like doing so. Hence, this chapter defines employee engagement in terms of both motivation and passion.

\section{Motivation}

Motivation is the "internal forces that direct, energize, and sustain work-related effort" (Chen \& Gogus, 2008, p. 290; Kanfer 1990). Motivation represents the degree to which someone is willing to exert and sustain effort (Chen, Kanfer, DeShon, Mathieu, \& Kozlowski, 2009). Humans are motivated to exert effort toward achieving a goal or objective (Kanfer, 1990). Motivational theories help to depict how the roles of goals and objectives can elicit human effort throughout an activity (Kanfer \& Ackerman, 1989; Parker, Bindl, \& Strauss, 2010).

Employee motivation can be viewed as the willingness of an employee to exert effort toward accomplishing his or her work. Employee motivation is a primary driver of both individual and work group performance (Chen \& Kanfer, 2006). In fact, the level of motivation and corresponding effort an employee exerts have strong impacts on performance (De Jong \& Elfring, 2010). This has been particularly highlighted in the literature investigating social loafing or withholding effort (Alnuaimi et al., 2010). Motivation is also positively associated with job satisfaction and work group retention(Chen, Sharma, Edinger, Shapiro, \& Farh, 2011; Hu \& Liden, 2014; Parker et al., 2010). In all, motivation is key determinant of important employee outcomes. 
Motivation is comprised of three core components: goal choice, goal striving, and self-belief in goal attainment (Chen \& Gogus, 2008). Goal choice is the process of selecting which objective or set of objectives to pursue (Parker et al., 2010). Goal striving reflects the amount of effort an employee allocates toward achieving that objective or set of objectives (Parker et al., 2010). Self-efficacy or the belief that one can achieve a given objective influences the amount of effort and persistence individuals allocate toward achieving their objective (Parker et al., 2010). In sum, self-efficacy, goal choice, and goal striving make up the motivational process that explains the effort an individual allocates toward achieving a goal (Klein et al., 2008). AI can support each of these processes.

\section{Artificial Intelligence Employee Controls}

To fully understand employee engagement and why it is important one should be familiar with theory $\mathrm{X}$ and theory $\mathrm{Y}$ of management. Theory $\mathrm{X}$ and theory $\mathrm{Y}$ of management represent two fundamental approaches to employee engagement (Carson, 2005). According to McGregor, theory X seeks to promote engagement by directing, monitoring, and rewarding and/or punishing the actions of employees, while theory $\mathrm{Y}$ seeks to promote engagement by promoting worker satisfaction through greater job autonomy and freedom and less supervision (Carson, 2005; Kopelman, Prottas, \& Davis, 2008). Both are valid approaches to worker engagement and have pros and cons. For better or for worse, AI management systems are based on theory X. AI management systems seek to promote worker engagement by directing, monitoring, and rewarding and/or punishing employee's actions. This approach is especially true for sharing economy platforms like Uber that enable the gig economy (Marquis et al., 2018). But, they can also be true for AI management systems in traditional organizations.

Organizational controls are used to get workers to act in a way that furthers the goals and objectives of the organization (Cardinal, Kreutzer, \& Miller, 2017). Behavior and outcome controls are two of the most widely used organizational controls (Cardinal et al., 2017). Behavioral control involves direct, personal surveillance of a worker's activities (Dennis et al., 2012). Outcome control involves an objective measurement or evaluation of the output of a worker's activities (Ouchi \& Maguire, 1975). Many platform companies employ AI management systems to control their workers. For example, the Uber app driven by AI tells the driver who to pick up, how to get there, and where to drop them off (Rosenblat \& Stark, 2016). Given the importance of organizational control in organizations, it is to be expected that control through AI management systems is likely to be very important.

\section{Artificial Intelligence Behavior Control}

AI behavior control entails the electronic directing and monitoring of an employee's work activities to make sure that they are complying with a predefined work standard. Generally, behavior controls are effective when both the organization and the employees know exactly how a task should be completed. 
For example, a retail store manager may monitor the way employees greet and interact with store customers to ensure they are following company policies. Behavior control has been shown to lead to high intrinsic motivation and positive attitudinal outcomes (Cardinal et al., 2017; Jaworski, Stathakopoulos, \& Krishnan, 1993; Sihag \& Rijsdijk, 2018). AI behavior control is often enacted through digital systems.

\section{Artificial Intelligence Outcome Control}

AI outcome control is enacted by measuring objective measurements of the employee's performance. Behavior control requires directly observing workers' activities, but outcome control involves evaluating workers' performance after the service is completed. Examples of outcome controls include monthly or quarterly sales targets and performance evaluations (Eisenhardt, 1985; Ouchi, 1979). Uber's rating system is an example of AI outcome control enacted through a digital platform. Uber drivers who fail to receive a performance rating of below $4.6 / 5$ can be suspended from driving for Uber.

\section{Artificial Intelligence Trust and Perceived Risk}

\section{Artificial Intelligence Trust}

Trust in an organization can be defined as an employee's willingness to be vulnerable to the actions of the organization (Dirks \& Ferrin, 2001; McAllister, 1995).

Based on this definition we define trust in an AI management system as an employee's willingness to be vulnerable to the actions of the AI management system. Employees should not only rely on their AI management system but do so with a positive expectation about the outcome. Both the willingness to be vulnerable and the assumption of a beneficial outcome explain why trust will be a crucial component in the effectiveness of any AI management system. Social exchange theory is often used to explain the benefits of trust (Dirks \& Ferrin, 2001).

According to social exchange theory, employees will take part in an activity only if they believe the result of their activity is likely to be satisfactory (Blau, 1964; Homans, 1961). For example, Uber drivers are more likely to follow the guidance provided by the AI management system when they believe that doing so will lead to a satisfactory outcome. Trust becomes more important when the level of uncertainty regarding the outcome increases (Robert et al., 2009). This is because when the outcome is uncertain, individuals do not know whether their actions will be rewarded with a positive outcome. For example, employees are less likely to follow the recommendations of the AI management system if there is a risk that doing so will not lead to a satisfactory outcome. Trust counteracts such risk by increasing the perceived certainty regarding the likelihood of a satisfactory outcome (Zand, 1972). The more employees trust the AI management system, the more willing they will be to take the advice from the system. Trust reduces anxiety and fears by allowing employees to rule out undesirable yet possible outcomes. For example, when Uber drivers are asked to relocate to pick up 
possible riders, the drivers are much more likely to do so when they believe Uber's AI management system will likely lead to a positive outcome.

\section{Artificial Intelligence Perceived Risk}

Perceived risk can be defined as the degree of uncertainty associated with an outcome (Sitkin \& Pablo, 1992). Perceived risk differentiates trust from the behaviors that require trust (Mayer, Davis, \& Schoorman, 1995). It is what determines whether an individual will translate trust beliefs into trusting actions. Organizations often minimize perceived risk by enacting organizational control systems like sanctions for violating trust or institutional structures to minimize losses (Sheppard \& Sherman, 1998; Sitkin \& Pablo, 1992). Individuals tend to be risk-averse (Friedman \& Savage, 1948) and weigh the risk of loss more heavily than the potential benefits (Tversky \& Kahneman, 1974). Different people might also have different perceptions of risks when presented with the same situation.

Employees are likely to associate perceived risk with marginal gains or losses associated with a given AI management system. For example, Uber drivers have some expectations about the amount of money they can make on a given transaction. They likely compare this to the amount of money they believe they are likely to make when following the guidance provided by AI management system. For example, if a driver has been asked to relocate to another location to serve a future rider, the driver might ask herself, "Will I make more money relocating than the money I am sure to make here?" or "Why am I being asked to relocate?" If drivers believe that the monetary outcome provided by AI management system is below their expected outcome, they are likely to ignore the system, either in the short or the long term.

\section{Artificial Intelligence Fairness}

The AI management system must convince employees that it is fair and justice. Generally, fairness can be viewed as the framework to explain employees' trust toward their organization (Saunders \& Thornhill, 2003). An employee's level of commitment to an employer is directly related to their belief that their employer treats them fairly (Hendrix, Robbins, Miller, \& Summers, 1998). Perceived fairness is derived from the organizational justice literature, which is based on Adams' (1965) equity theory. Equity theory states that individuals believe that the distribution of rewards should be based on an individual's contribution. In organizations, equity typically refers to the expected inputs by an employee relative to the outcomes the employee expects to receive from his or her employer (Colquitt, 2012). Employees compare their input and outcomes to that of other employees and expect to see roughly the same input-to-outcome ratio (Cowherd \& Levine, 1992; Hendrix et al., 1998). When a discrepancy is detected, employees will attempt to resolve it in one of three ways: (1) altering their perceptions of the inputs and outcomes, (2) changing their inputs, or (3) leaving the organization (Cowherd \& Levine 1992; Hopkins \& Weathington, 2006). There are three widely used types of perceived fairness: procedural, distributive, and 
interactional fairness (Greenberg \& Colquitt, 2013). Employees are likely to determine if AI management systems are based on each of these three types.

\section{Artificial Intelligence Procedural Fairness}

Procedural fairness is the perceived fairness of the processes used by the organization (Hendrix et al., 1998: Holbrook, 1999; Saunders \& Thornhill, 2003). These processes manifest themselves in how fair employees believe that the AI management system decision process is to each employee. Procedural fairness will be low (1) when employees believe the AI management system decision processes are inconsistent or biased and/or (2) whether employees can express their concerns regarding such decisions (Leventhal, 1980). For example, procedural fairness for employees managed by AI systems would represent the way complaints are handled, how their performance is evaluated, or their ability to voice their concern over new policies.

\section{Artificial Intelligence Distributive Fairness}

Distributive fairness refers to the perceived fairness of outcomes and allocation of resources (Greenberg \& Colquitt, 2013). These outcomes and resources are normally in the form of pay or praise. When an employee believes the AI management system leads to employees receiving equal pay for equal work, distributive fairness should be high. However, when employees believe their use of the AI management system either leads to or exacerbates pay inequalities, distributive fairness should be low.

\section{Artificial Intelligence Interactional Fairness}

Interactional fairness relates to the treatment employees receive as decisions are made, and this can be broken into interpersonal and informational justice (Colquitt, Conlon, Wesson, Porter, \& Ng, 2001). Interpersonal fairness can be defined as the degree of respect employees are provided, while informational fairness refers to the information provided regarding why procedures are carried out and why outcomes are distributed (Colquitt, 2012). For employees being managed by AI management systems, interaction fairness would refer to what degree they think the AI respects them and provides an explanation for its decisions.

\section{Artificial Intelligence Technology Characteristics}

Perceived ease of use and usefulness are two important technology characteristics. They have been found to be important predictors of technology use (Venkatesh, Morris, Davis, \& Davis, 2003). More recently, they have been used to predict the use of digital platforms involving electronic commerce sites such as eBay (Gefen, Karahanna, \& Straub, 2003; Pavlou, 2003). Their importance has also been tied to trust in the customers' use of AI management systems 
(Xiao \& Benbasat, 2007). Therefore, we include both ease of use and usefulness to better understand trust and its implications for the use of AI management systems.

\section{Artificial Intelligence Perceived Ease of Use}

Perceived ease of use is defined as the degree employees believe the system is straightforward and relatively trouble-free to use (Venkatesh et al., 2003). Systems high in ease of use require little effort to employ and are not very difficult to learn. Employees will use systems more often when they believe they will experience little difficulty in using them (Venkatesh \& Davis, 2000). When systems are not easy to use, anticipated difficulties often act as psychological barriers to employing systems (Venkatesh, Thong, \& Xu, 2012). As such, employees managed by AI systems would be less likely to engage with AI management systems if they found it difficult to interact with. On the other hand, employees managed by AI systems would be more willing to engage them if they believed it to be easy to use.

\section{Artificial Intelligence Perceived Usefulness}

Perceived usefulness is defined as the degree employees believe that using the system will benefit them (Venkatesh et al., 2012). This normally pertains to either better job performance or a decrease in the time needed to perform the same amount of work. When employees believe a system is useful, they are much more likely to employ the system to perform their work (Venkatesh et al., 2003). In the case of AI, we should expect drivers to trust and employ AI when they believe it is useful. We should expect the opposite when they believe the system is not useful.

\section{Artificial Intelligence, Job Satisfaction, Job Meaningfulness, and Retention}

Throughout the literature on the management of employees three outcomes are often considered vital to understanding if management practices are successful: job satisfaction, job meaningfulness, and employee retention. Job satisfaction can be defined as the degree of positive attitude workers have toward their job (Beer, 1964). Job meaningfulness is the degree to which someone feels that his or her job is worthwhile, useful, and valuable (Kahn, 1990). Employee retention is a measure of how many employees are retained by an organization (Carsten \& Spector, 1987; Iverson \& Pullman, 2000). Taken together, all three represent important measures of employee outcomes.

Research has shown that relationships and interactions with others in the workplace are vital to promoting job satisfaction, meaningfulness, and retention (Karasek, Triantis, \& Chaudhry, 1982; Tett \& Meyer, 1993). These relationships and interactions include informal conversations with colleagues and formal feedback and mentoring from supervisors (Bateman, 2009; Fay \& Kline, 2011). In 
fact, social support derived from such interactions with both colleagues and supervisors is often the primary driver of employee outcomes like job satisfaction, meaningfulness, and retention (Bateman, 2009; Carsten \& Spector, 1987; Ross, 2005). This is because humans are social beings who need interactions with other humans (Taneja et al., 2011). Yet, the use of AI systems could possibly reduce or eliminate such social interactions.

How can organizations with employees managed primarily by AI systems promote social interactions? One approach is to build online communities on digital platforms. This approach is similar to many current communities sponsored by companies like Uber or Airbnb. Organizations can set up their own online communities to allow employees to interact not only with other employees but also with the company. These online communities can both build "community" among employees and allow companies to contact and assess the needs of their employees. Of course, issues of privacy should not be overlooked. Organizations must seek and receive approval from employees before monitoring their online actions. That withstanding, this approach can help replace traditional social interactions which seem lost in these new digital AI-enabled work arrangements.

\section{Conclusion}

Artificial Intelligence is used to manage employees through employee engagement. This occurs by motivating employees and controlling their actions. However, issues of trust, perceived risk, and fairness play a vital role in determining whether such systems will be effective at managing employees over the long run. In addition, AI-driven systems must be easy to use and be viewed as useful if companies hope to encourage their use. This chapter presents and discusses these issues along employee outcomes such as job satisfaction, meaningfulness, and employee retention. 


\section{References}

Adams, J. S. (1965). Inequity in social exchange. Advances in Experimental Social Psychology, 2, 267-299.

Alnuaimi, O. A., Robert, L. P., \& Maruping, L. M. (2010). Team size, dispersion, and social loafing in technology supported teams: A theory of moral disengagement perspective. Journal of Management Information Systems, 27(1), 203-230.

Bateman, G. (2009). Employee perceptions of co-worker support and its effect on job satisfaction, work stress and intention to quit. Unpublished dissertation, University of Canterbury.

Beer, M. (1964). Organizational size and job satisfaction. Academy of Management Journal, 7(1), 34-44.

Blau, P. M. (1964). Exchange and power in social life. New Brunswick, NJ: Transaction Publishers.

Cardinal, L. B., Kreutzer, M., \& Miller, C. C. (2017). An aspirational view of organizational control research: Re-invigorating empirical work to better meet the challenges of 21 st century organizations. Academy of Management Annals, 11, 559592.

Carson, C. M. (2005). A historical view of Douglas McGregor's theory Y. Management Decision, 43, 450-460.

Carsten, J. M., \& Spector, P. E. (1987). Unemployment, job satisfaction, and employee turnover: A meta-analytic test of the Muchinsky model. Journal of Applied Psychology, 72(3), 374-381.

Chen, G., \& Kanfer, R. (2006). Towards a systems theory of motivated behavior in work teams. In R. M. Kramer \& B. Staw (Eds.), Research in organizational behavior: An annual series of analytical essays and critical reviews (Vol. 27, pp. 223-267). Oxford: Elsevier.

Chen, G., Kanfer, R., DeShon, R. P., Mathieu, J. E., \& Kozlowski, S. W. J. (2009). The motivating potential of teams: Test and extension of Chen and Kanfer's (2006) crosslevel model of motivation in teams. Organizational Behavior and Human Decision Processes, 110(1), 45-55.

Chen, G., Sharma, P. N., Edinger, S. K., Shapiro, D. L., \& Farh, J. L. (2011). Motivating and demotivating forces in teams: cross-level influences of empowering leadership and relationship conflict. Journal of Applied Psychology, 96, 541-557.

Chen, G., \& Gogus, C. I. (2008). Motivation in and of work teams: A multilevel perspective. In R. Kanfer, G. Chen, \& R. D. Pritchard (Eds.), Work motivation: Past, Present, and Future (pp. 285-318). New York, NY: Routledge.

Colquitt, J. A. (2012). Organizational justice. In S. J. W. Kozlowski (Ed.), The Oxford handbook of organizational psychology (Vol. 1, pp. 526-547). New York, NY: Oxford University Press. 
Colquitt, J. A., Conlon, D. E., Wesson, M. J., Porter, C. O., \& Ng, K. Y. (2001). Justice at the millennium: A meta-analytic review of 25 years of organizational justice research. Journal of Applied Psychology, 86, 425-445.

Cowherd, D. M., \& Levine, D. I. (1992). Product quality and pay equity between lower-level employees and top management: An investigation of distributive justice theory. Administrative Science Quarterly, 37, 302-320.

De Jong, B. A., \& Elfring, T. (2010). How trust affects performance of ongoing teams. Academy of Management Journal, 53, 535-549.

Dennis, A. R., Robert, L. P., Kowalczyck, S. T., Curtis, A., \& Hasty, B. K. (2012). Trust is in the eye of the beholder: A vignette study of postevent behavioral controls' effects on individual trust in virtual teams. Information Systems Research, 23, 546-558.

Dirks, K. T., \& Ferrin, D. L. (2001). The role of trust in organizational settings. Organization Science, 12, 450-467.

Eisenhardt, K. M. (1985). Control: Organizational and economic approaches. Management Science, 31(2), 134-149.

Fay, M. J., \& Kline, S. L. (2011). Coworker relationships and informal communication in high-intensity telecommuting. Journal of Applied Communication Research, 39(2), 144-163.

Friedman, M., \& Savage, L. J. (1948). The utility analysis of choices involving risk. The Journal of Political Economy, 56, 279-304.

Gefen, D., Karahanna, E., \& Straub, D. W. (2003). Trust and TAM in online shopping: an integrated model. MIS Quarterly, 27(1), 51-90.

Gerlsbeck, R. (2018). The AI manager. Smith Magazine, Summer Issue. Retrieved from https://smith.queensu.ca/magazine/summer-2018/features/ai-manager.

Greenberg, J., \& Colquitt, J. A. (Eds.). (2013). Handbook of organizational justice. New York, NY: Psychology Press.

Hendrix, W. H., Robbins, T., Miller, J., \& Summers, T. P. (1998). Effects of procedural and distributive justice on factors predictive of turnover. Journal of Social Behavior and Personality, 13, 611-632.

Homans, G. C. (1961). Social behavior: Its elementary forms. New York, NY: Harcourt, Brace.

Holbrook, R. L. (1999). Managing reactions to performance appraisal: The influence of multiple justice mechanisms. Social Justice Research, 12(3), 205-221.

Hopkins, S. M., \& Weathington, B. L. (2006). The relationships between justice perceptions, trust, and employee attitudes in a downsized organization. The Journal of Psychology, 140, 477-498. 
$\mathrm{Hu}$, J., \& Liden, R. (2014). Making a difference in the teamwork: Linking team prosocial motivation to team processes and effectiveness. Academy of Management Journal, 58, 1102-1127. doi:10.5465/amj.2012.1142

Iverson, R. D., \& Pullman, J. A. (2000). Determinants of voluntary turnover and layoffs in an environment of repeated downsizing following a merger: An event history analysis. Journal of Management, 26, 977-1003.

Jaworski, B. J., Stathakopoulos, V., \& Krishnan, H. S. (1993). Control combinations in marketing: conceptual framework and empirical evidence. Journal of Marketing, 57(1), 57-69.

Kahn, W. A. (1990). Psychological conditions of personal engagement and disengagement at work. Academy of Management Journal, 33, 692-724.

Kanfer, R., \& Ackerman, P. L. (1989). Motivation and cognitive abilities: An integrative/ aptitude-treatment interaction approach to skill acquisition. Journal of Applied Psychology, 74, 657-690.

Kanfer, R. (1990). Motivation theory and industrial and organizational psychology. In M. D. Dunnette \& L. M. Hough (Eds.), Handbook of industrial and organizational psychology (2nd ed., Vol. 1, pp. 75-170). Palo Alto, CA: Consulting Psychologists Press.

Karasek, R. A., Triantis, K. P., \& Chaudhry, S. S. (1982). Coworker and supervisor support as moderators of associations between task characteristics and mental strain. Journal of Organizational Behavior, 3(2), 181-200.

Kolbjørnsrud, V., Amico, R., \& Thomas, R. J. (2016). How artificial intelligence will redefine management. Harvard Business Review, 2-6.

Kopelman, R. E., Prottas, D. J., \& Davis, A. L. (2008). Douglas McGregor's theory X and Y: Toward a construct-valid measure. Journal of Managerial Issues, 20(2), 255271 .

Klein, H. J., Austin, J. T., \& Cooper, J. T. (2008). Goal choice and decision processes. In R. Kanfer, G. Chen, \& R. Pritchard (Eds.) Work motivation: Past, present, and future (pp. 101-150). New York, London: Routledge/Taylor \& Francis Group.

Leventhal, G. S. (1980). What should be done with equity theory? In K. J. Gergen, M. S. Greenberg, \& R. H. Willis (Eds.). Social exchange (pp. 27-55). Boston, MA: Springer.

Mayer, R. C., Davis, J. H., \& Schoorman, F. D. (1995). An integrative model of organizational trust. Academy of Management Review, 20, 709-734.

Marquis, E., Kim, S., Alahmad, R., Pierce, C., \& Robert, L. P. (2018). Behavioral control and emotional labor among gig economy workers. Proceedings of the $21^{\text {st }}$ ACM Conference on Computer Supported Cooperative Work and Social Computing Companion. New Jersey, NJ. http://10.1145/3272973.3274065.

McAllister, D. J. (1995.) Affect-and cognition-based trust as foundations for interpersonal cooperation in organizations. Academy of Management Journal, 38(1), 24-59. 
O' Connor, S. (2016, September). When your boss is an algorithm. Financial Times. Retrieved from https://www.ft.com/content/88fdc58e-754f-11e6-b60a-de4532d5ea35

Ouchi, W. G., \& Maguire, M. A. (1975). Organizational control: Two functions. Administrative Science Quarterly, 20, 559-569.

Ouchi, W. G. (1979). A conceptual framework for the design of organizational control mechanisms. Management Science, 25, 833-848.

Parker, S. K., Bindl, U. K., \& Strauss, K. (2010). Making things happen: A model of proactive motivation. Journal of Management, 36, 827-856.

Pavlou, P. A., (2003). Consumer acceptance of electronic commerce: Integrating trust and risk with the technology acceptance model. International Journal of Electronic Commerce, 7(3), 101-134.

Rao, M. S. (2017). Innovative tools and techniques to ensure effective employee engagement. Industrial and Commercial Training, 49(3), 127-131.

Robert, L. P., Dennis, A. R., \& Hung, C. (2009). Individual swift trust and knowledgebased trust in face to face and virtual team members. Journal of Management Information Systems, 26(2), 241-279.

Rothbard, N. P. (2001). Enriching or depleting? The dynamics of engagement in work and family roles. Administrative Science Quarterly, 46, 655-684.

Rosenblat, A., \& Stark, L. (2016). Algorithmic labor and information asymmetries: A case study of Uber's drivers. International Journal of Communication, 10, 3758-3784.

Ross, J. A. (2005). Dealing with the real reasons people leave. Harvard Management Update, 10(8), 1.

Saks, A. M. (2006). Antecedents and consequences of employee engagement. Journal of Managerial Psychology, 21, 600-619.

Saunders, M. N., \& Thornhill, A. (2003). Organizational justice, trust and the management of change: An exploration. Personnel Review, 32(3), 360-375.

Sheppard, B. H., \& Sherman, D. M. (1998). The grammars of trust: A model and general implications. Academy of Management Review, 23, 422-437.

Shuck, B., Adelson, J. L., \& Reio, T. G. (2017). The employee engagement scale: Initial evidence for construct validity and implications for theory and practice. Human Resource Management, 56, 953-977.

Shuck, B., Osam, K., Zigarmi, D., \& Nimon, K. (2017). Definitional and conceptual muddling: Identifying the positionality of employee engagement and defining the construct. Human Resource Development Review, 16, 263-293.

Sihag, V., \& Rijsdijk, S. A. (2018). Organizational controls and performance outcomes:a meta-analytic assessment and extension. Journal of Management Studies, 1-43. doi:10.1111/joms. 12342. 
Sitkin, S. B., \& Pablo, A. L. (1992). Reconceptualizing the determinants of risk behavior. Academy of Management Review, 17(1), 9-38.

Taneja, S., Pryor, M. G., \& Toombs, L. A. (2011). Frederick W. Taylor's scientific management principles: Relevance and validity. Journal of Applied Management and Entrepreneurship, 16(3), 60.

Tett, R. P., \& Meyer, J. P. (1993). Job satisfaction, organizational commitment, turnover intention, and turnover: Path analyses based on meta-analytic findings. Personnel Psychology, 46(2), 259-293.

Tversky, A., \& Kahneman, D. (1974). Judgment under uncertainty: Heuristics and biases. Science, 185, 1124-1131.

Venkatesh, V., \& Davis, F. D. (2000). A theoretical extension of the technology acceptance model: Four longitudinal field studies. Management Science, 46(2), 186204.

Venkatesh, V., Morris, M. G., Davis, G. B., \& Davis, F. D. (2003). User acceptance of information technology: Toward a unified view. MIS Quarterly, 27, 425-478.

Venkatesh, V., Thong, J. Y., \& Xu, X. (2012). Consumer acceptance and use of information technology: Extending the unified theory of acceptance and use of technology. MIS Quarterly, 36(1), 157-178.

Xiao, B., \& Benbasat, I. (2007). E-commerce product recommendation agents: Use, characteristics, and impact. MIS Quarterly, 31(1), 137-209.

Zand, D. E. (1972). Trust and managerial problem solving. Administrative Science Quarterly, 17(2), 229. 
